\title{
AIRWAY TOPICALIZATION IN THE MORBIDLY OBESE USING ATOMIZED LIDOCAINE
}

Paul M. Wieczorek MDCM ${ }^{1}$, Thomas Schricker MD $\mathrm{PhD}^{1}$, Bernard Vinet $\mathrm{PhD}{ }^{2}$, Steven B. Backman MDCM PhD FRCPC ${ }^{1}$.

${ }^{1}$ Dept. Anesthesia, Royal Victoria Hospital and McGill University. 687 Pine Ave. W. Montreal QC, H3Y 3E7, and ${ }^{2}$ Dept. Biochemistry, Hôpital Notre-Dame and L'Université de Montréal, 1560 Sherbrooke E, Montreal QC, H2L 4M1

INTRODUCTION: Appropriate airway management in the morbidly obese is critical. We evaluated the technique of airway topicalization with atomized $4 \%$ lidocaine.

METHODS: Following research ethics board approval and informed consent, morbidly obese patients undergoing gastric bypass were sedated with midazolam and fentanyl, titrated to effect, following aspiration prophylaxis (sodium citrate $0.3 \mathrm{M} 30 \mathrm{ml} \mathrm{PO}$; metaclopramide $10 \mathrm{mg}$; ondansetron $4 \mathrm{mg}$ ). Glycopyrrolate $(0.3$ $\mathrm{mg}$ ) was given as an antisialogogue. Lidocaine (4\%, $40 \mathrm{ml})$, administered via an atomizer using high-flow oxygen, was inhaled orally (nares clamped). Awake fiberoptic intubation proceeded, followed by induction of general anesthesia. End-points included serial plasma lidocaine concentrations, blood pressure and heart rate, and patient tolerance during placement of the Ovassapian airway, bronchoscopy and endotracheal tube placement $(0=$ no response; $1=$ some gagging; $2=$ not tolerable $)$.

RESULTS: Eleven patients were studied. Demographic data included gender (M/F:3/8), age (41.8 $\pm 2.7 \mathrm{yrs,}$ mean \pm SEM), height $(168.1 \pm 2.4 \mathrm{~cm})$, weight $(145.5 \pm 7.4 \mathrm{~kg})$, and BMI $\left(51.6 \pm 2.2 \mathrm{~kg} / \mathrm{m}^{2}\right)$. Patients received midazolam $2.6 \pm 0.2 \mathrm{mg}$ and fentanyl $161.1 \pm 18.2 \mu \mathrm{g}$ for sedation. Peak plasma concentration occurred within 10 minutes of termination of topicalization (Figure). Regression analysis demonstrated no relationship between peak concentration and height, weight, or BMI. Clinical signs of toxicity were not observed. Blood pressure and heart rate did not change significantly during topicalization and intubation. Time for airway topicalization was $4.7 \pm 0.4$ minutes, and airway management (start of topicalization to endotracheal tube cuff inflation) occurred in $7.8 \pm 0.7 \mathrm{~min}$. Excellent intubating conditions were achieved as indicated by the tolerance scores for insertion of the Ovassapian airway, bronchoscopy, and endotracheal tube placement (1, 2 , and 2 patients had mild gagging respectively)..

DISCUSSION: This is the first study evaluating the technique of airway topicalization using atomized lidocaine for awake fiberoptic intubation. This technique provided excellent conditions for securing the airway rapidly and safely in morbidly obese patients who are at high risk for a difficult airway. The initial high plasma concentration of lidocaine was unanticipated and is of some concern. Lower doses for airway topicalization are currently being evaluated in this unique patient population.

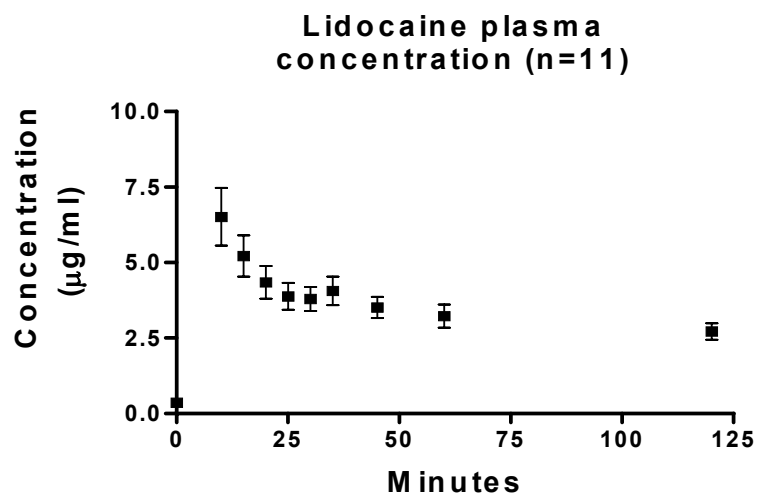

